\title{
Mohand Transform of Error Function
}

\author{
Sudhanshu Aggarwal ${ }^{1 *}$, Anjana Rani Gupta ${ }^{2}$, Deepak Kumar ${ }^{3}$ \\ ${ }^{1}$ Assistant Professor, Department of Mathematics, National P.G. College Barhalganj, \\ Gorakhpur-273402, U.P., India \\ ${ }^{2}$ Professor, Department of Mathematics, Noida Institute of Engineering \& Technology, \\ Greater Noida-201306, U.P., India \\ ${ }^{3}$ Associate Professor, Department of Applied Sciences, Galgotia College of Engineering and Technology, \\ Greater Noida-201306, U.P. India \\ sudhanshu30187@gmail.com,argad76@gmail.com,drdeepak.kumar@galgotiacollege.edu
}

\begin{abstract}
The solutions of many advanced engineering problems like Fick's second law, heat and mass transfer problems, vibrating beams problems contains error and complementary error function. When we use any integral transform to solve these types of problems, it is very necessary to know the integral transform of error function. In this article, we find the Mohand transform of error and complementary error functions. To demonstrate the usefulness of Mohand transform of error function, some numerical applications are considered in application section for solving improper integrals which contain error function. It is pointed out that Mohand transform give the exact solution of improper integral which contains error function without any tedious calculation work.
\end{abstract}

Keywords: Mohand transform, Error function, Complementary error function, Improper integral.

AMS Subject Classification: 44A05, 44A20, 44A35.

\section{INTRODUCTION:}

Integral transforms are highly efficient for solving many advance problems of science and engineering such as radioactive decay problems, heat conduction problems, problem of motion of a particle under gravity, vibration problems of beam, electric circuit problems and population growth problems. Many researchers applied different integral transforms (Laplace transform [1-2], Fourier transform [2], Mahgoub transform [3-11, 41-43], Kamal transform [12-18, 44-45], Aboodh transform [19-24, 46-48], Mohand transform [25-28, 49-52], Elzaki transform [34-36, 53-55], Shehu transform [37-38, 56] and Sumudu transform $[39,57-58]$ ) and solved differential equations, delay differential equations, partial differential equations, integral equations, integrodifferential equations and partial integro-differential equations. Sudhanshu et al. [29-33, 40] discussed the comparative study of Mohand and other transforms (Laplace transform, Kamal transform, Elzaki transform, Aboodh transform, Sumudu transform and Mahgoub transform).

Error function occurs frequently in probability, physics, statistics, mathematics and many engineering problems like heat conduction problems, vibrating beams problems etc. Mathematically error and complimentary error functions are defined by [59-64]

$\operatorname{erf}(x)=\frac{2}{\sqrt{\pi}} \int_{0}^{x} e^{-t^{2}} d t$ and

$\operatorname{erfc}(x)=\frac{2}{\sqrt{\pi}} \int_{x}^{\infty} e^{-t^{2}} d t$

In 2017, Mohand and Mahgoub [49] defined a new integral transform "Mohand transform" of the function $F(t)$ for $t \geq 0$ as

$M\{F(t)\}=v^{2} \int_{0}^{\infty} F(t) e^{-v t} d t=R(v), k_{1} \leq v \leq k_{2}$

where operator $M$ is called the Mohand transform operator.

The main purpose of the present article is to determine Mohand transform of error function and explain the importance of Mohand transform of error function by giving some numerical applications in application section of this paper.

\section{SOME USEFUL PROPERTIES OF MOHAND TRANSFORM:}

2.1 Linearity property [9-11]:

If Mohand transform of functions $F_{1}(t)$ and $F_{2}(t)$ are $R_{1}(v)$ and $R_{2}(v)$ respectively then Mohand transform of $\left[a F_{1}(t)+b F_{2}(t)\right]$ is given by $\left[a R_{1}(v)+\right.$ $\left.b R_{2}(v)\right]$, where $a, b$ are arbitrary constants.

Proof: By the definition of Mohand transform, we have $M\{F(t)\}=v^{2} \int_{0}^{\infty} F(t) e^{-v t} d t$ 


$$
\begin{aligned}
& \Rightarrow M\left\{a F_{1}(t)+b F_{2}(t)\right\} \\
& =v^{2} \int_{0}^{\infty}\left[a F_{1}(t)+b F_{2}(t)\right] e^{-v t} d t \\
& \Rightarrow M\left\{a F_{1}(t)+b F_{2}(t)\right\} \\
& =a v^{2} \int_{0}^{\infty} F_{1}(t) e^{-v t} d t \\
& +b v^{2} \int_{0}^{\infty} F_{2}(t) e^{-v t} d t \\
& \Rightarrow M\left\{a F_{1}(t)+b F_{2}(t)\right\}=a M\left\{F_{1}(t)\right\}+b M\left\{F_{2}(t)\right\} \\
& \Rightarrow M\left\{a F_{1}(t)+b F_{2}(t)\right\}=a R_{1}(v)+b R_{2}(v) \text {, } \\
& \text { where } a, b \text { are arbitrary constants. }
\end{aligned}
$$

Proof: By the definition of Mohand transform, we have $M\{F(a t)\}=v^{2} \int_{0}^{\infty} F(a t) e^{-v t} d t$

Put $a t=p \Rightarrow a d t=d p$ in equation(4), we have

$M\{F(a t)\}=\frac{v^{2}}{a} \int_{0}^{\infty} F(p) e^{\frac{-v p}{a}} d p$

$\Rightarrow M\{F(a t)\}=a\left[\frac{v^{2}}{a^{2}} \int_{0}^{\infty} F(p) e^{\frac{-v p}{a}} d p\right]$

$\Rightarrow M\{F(a t)\}=a R\left(\frac{v}{a}\right)$

\subsection{Shifting property [11]:}

If Mohand transform of function $F(t)$ is $R(v)$ then Mohand transform of function $e^{a t} F(t)$ is given by $\frac{v^{2}}{(v-a)^{2}} R(v-a)$.

Proof: By the definition of Mohand transform, we have

$$
\begin{gathered}
M\left\{e^{a t} F(t)\right\}=v^{2} \int_{0}^{\infty} e^{a t} F(t) e^{-v t} d t \\
=v^{2} \int_{0}^{\infty} F(t) e^{-(v-a) t} d t \\
=\frac{v^{2}}{(v-a)^{2}}(v-a)^{2} \int_{0}^{\infty} F(t) e^{-(v-a) t} d t \\
=\frac{v^{2}}{(v-a)^{2}} R(v-a)
\end{gathered}
$$

2.4 Mohand transform of the derivatives of the function $\boldsymbol{F}(\boldsymbol{t})$ [7-8, 10]:

If $M\{F(t)\}=R(v)$ then
a) $M\left\{F^{\prime}(t)\right\}=v R(v)-v^{2} F(0)$
b) $M\left\{F^{\prime \prime}(t)\right\}=v^{2} R(v)-v^{3} F(0)-v^{2} F^{\prime}(0)$
c) $M\left\{F^{(n)}(t)\right\}=v^{n} R(v)-v^{n+1} F(0)-v^{n} F^{\prime}(0)$ $\cdots \ldots-v^{2} F^{(n-1)}(0)$

2.5 Mohand transform of integral of a function $\boldsymbol{F}(\boldsymbol{t})$ : If $M\{F(t)\}=R(v)$ then $M\left\{\int_{0}^{t} F(t) d t\right\}=\frac{1}{v} R(v)$

Proof: Let $G(t)=\int_{0}^{t} F(t) d t$. Then $G^{\prime}(t)=F(t)$ and $G(0)=0$.
Now by the property of Mohand transform of the derivative of function, we have

$$
\begin{aligned}
& M\left\{G^{\prime}(t)\right\}=v M\{G(t)\}-v^{2} G(0)=v M\{G(t)\} \\
& \Rightarrow M\{G(t)\}=\frac{1}{v} M\left\{G^{\prime}(t)\right\}=\frac{1}{v} M\{F(t)\} \\
& \Rightarrow M\{G(t)\}=\frac{1}{v} R(v) \\
& \Rightarrow M\left\{\int_{0}^{t} F(t) d t\right\}=\frac{1}{v} R(v)
\end{aligned}
$$

2.6 Mohand transform of function $\boldsymbol{t} F(t)$ :

If $M\{F(t)\}=R(v)$ then $M\{t F(t)\}=\left[\frac{2}{v}-\frac{d}{d v}\right] R(v)$

Proof: By the definition of Mohand transform, we have

$$
\begin{aligned}
& M\{F(t)\}=v^{2} \int_{0}^{\infty} F(t) e^{-v t} d t=R(v) \\
& \Rightarrow \frac{d}{d v} R(v)=2 v \int_{0}^{\infty} F(t) e^{-v t} d t \\
& +v^{2} \int_{0}^{\infty}(-t) F(t) e^{-v t} d t \\
& \Rightarrow \frac{d}{d v} R(v)=\frac{2}{v} \cdot v^{2} \int_{0}^{\infty} F(t) e^{-v t} d t \\
& -v^{2} \int_{0}^{\infty} t F(t) e^{-v t} d t \\
& \Rightarrow \frac{d}{d v} R(v)=\frac{2}{v} R(v)-M\{t F(t)\} \\
& \Rightarrow M\{t F(t)\}=\left[\frac{2}{v}-\frac{d}{d v}\right] R(v)
\end{aligned}
$$

\subsection{Convolution theorem for Mohand transforms}

[11]:

If Mohand transform of functions $F_{1}(t)$ and $F_{2}(t)$ are $R_{1}(v)$ and $R_{2}(v)$ respectively then Mohand transform of their convolution $F_{1}(t) * F_{2}(t)$ is given by

$M\left\{F_{1}(t) * F_{2}(t)\right\}=\frac{1}{v^{2}} M\left\{F_{1}(t)\right\} M\left\{F_{2}(t)\right\}$

$\Rightarrow M\left\{F_{1}(t) * F_{2}(t)\right\}=\frac{1}{v^{2}} R_{1}(v) R_{2}(v)$, where $F_{1}(t) *$

$F_{2}(t)$ is defined by

$F_{1}(t) * F_{2}(t)=\int_{0}^{t} F_{1}(t-x) F_{2}(x) d x$

$=\int_{0}^{t} F_{1}(x) F_{2}(t-x) d x$

3. MOHAND TRANSFORM OF FREQUENTLY ENCOUNTERED FUNCTIONS [7-11]:

Table: 1

\begin{tabular}{|c|c|c|}
\hline S.N. & $F(t)$ & $M\{F(t)\}=R(v)$ \\
\hline 1. & 1 & $v$ \\
\hline 2. & $t$ & 1 \\
\hline 3. & $t^{2}$ & $\frac{2 !}{v}$ \\
\hline 4. & $t^{n}, n \in N$ & $\frac{n !}{v^{n-1}}$ \\
\hline
\end{tabular}




\begin{tabular}{|c|c|c|}
\hline 5. & $t^{n}, n>-1$ & $\frac{\Gamma(n+1)}{v^{n-1}}$ \\
\hline 6. & $e^{a t}$ & $\frac{v^{2}}{v-a}$ \\
\hline 7. & sinat & $\frac{a v^{2}}{\left(v^{2}+a^{2}\right)}$ \\
\hline 8. & cosat & $\frac{v^{3}}{\left(v^{2}+a^{2}\right)}$ \\
\hline 9. & sinhat & $\frac{a v^{2}}{\left(v^{2}-a^{2}\right)}$ \\
\hline 10. & coshat & $\frac{v^{3}}{\left(v^{2}-a^{2}\right)}$ \\
\hline
\end{tabular}

4. SOME IMPORTANT PROPERTIES OF ERROR AND COMPLEMENTARY ERROR FUNCTIONS:

4.1 The sum of error and complementary error functions is unity:

$\operatorname{erf}(x)+\operatorname{erfc}(x)=1$

Proof: we have $\int_{0}^{\infty} e^{-t^{2}} d t=\frac{\sqrt{\pi}}{2}$

$\Rightarrow \frac{2}{\sqrt{\pi}} \int_{0}^{\infty} e^{-t^{2}} d t=1$

$\Rightarrow \frac{2}{\sqrt{\pi}} \int_{0}^{x} e^{-t^{2}} d t+\frac{2}{\sqrt{\pi}} \int_{x}^{\infty} e^{-t^{2}} d t=1$

$\Rightarrow \operatorname{erf}(x)+\operatorname{erfc}(x)=1$

4.2 Error function is an odd function:

$\operatorname{erf}(-x)=-\operatorname{erf}(x)$

4.3 The value of error function at $x=0$ is 0 :

$\operatorname{erf}(0)=0$.

4.4 The value of complementary error function at $\boldsymbol{x}=\mathbf{0}$ is $\mathbf{1}$ :

$\operatorname{erfc}(0)=1$.

4.5 The domain of error and complementary error functions is $(-\infty, \infty)$.

4.6 erf $(x) \rightarrow 1$ as $x \rightarrow \infty$.

4.7 erfc $(x) \rightarrow 0$ as $x \rightarrow \infty$.

4.8 The value of error functions $\operatorname{erf}(x)$ for different values of $x$ [60]:

Table: 2

\begin{tabular}{|l|l|l|}
\hline S.N. & \multicolumn{1}{|c|}{$x$} & \multicolumn{1}{|c|}{$\operatorname{erf}(x)$} \\
\hline 1. & 0.00 & 0.00000 \\
\hline 2. & 0.02 & 0.02256 \\
\hline 3. & 0.04 & 0.04511 \\
\hline 4. & 0.06 & 0.06762 \\
\hline 5. & 0.08 & 0.09008 \\
\hline 6. & 0.10 & 0.11246 \\
\hline 7. & 0.12 & 0.13476 \\
\hline 8. & 0.14 & 0.15695 \\
\hline
\end{tabular}

\begin{tabular}{|l|l|l|}
\hline 9. & 0.16 & 0.17901 \\
\hline 10. & 0.18 & 0.20094 \\
\hline 11. & 0.20 & 0.22270 \\
\hline
\end{tabular}

\section{MOHAND TRANSFORM OF ERROR}

\section{FUNCTION:}

By equation (1), we have

$\operatorname{erf}(\sqrt{t})=\frac{2}{\sqrt{\pi}} \int_{0}^{\sqrt{t}} e^{-x^{2}} d x$

$=\frac{2}{\sqrt{\pi}} \int_{0}^{\sqrt{t}}\left[1-\frac{x^{2}}{1 !}+\frac{x^{4}}{2 !}-\frac{x^{6}}{3 !}+\cdots \ldots\right] d x$

$=\frac{2}{\sqrt{\pi}}\left[x-\frac{x^{3}}{3.1 !}+\frac{x^{5}}{5.2 !}-\frac{x^{7}}{7.3 !}+\cdots \ldots\right] \begin{gathered}\sqrt{t} \\ 0\end{gathered}$

$=\frac{2}{\sqrt{\pi}}\left[t^{1 / 2}-\frac{t^{3 / 2}}{3.1 !}+\frac{t^{5 / 2}}{5.2 !}-\frac{t^{7 / 2}}{7.3 !}+..\right]$

Applying Mohand transform both sides on equation(5), we get

$M\{\operatorname{erf}(\sqrt{t})\}=\frac{2}{\sqrt{\pi}} M\left\{\left[t^{1 / 2}-\frac{t^{3 / 2}}{3.1 !}+\frac{t^{5 / 2}}{5.2 !}-\frac{t^{7 / 2}}{7.3 !}+..\right]\right\}$

Applying the linearity property of Mohand transform on equation (6), we get

$$
\begin{gathered}
\begin{array}{c}
M\{\operatorname{erf}(\sqrt{t})\}=\frac{2}{\sqrt{\pi}}\left[\Gamma(3 / 2) v^{1 / 2}-\frac{\Gamma(5 / 2)}{v^{1 / 2} \cdot 3.1 !}\right. \\
\left.+\frac{\Gamma(7 / 2)}{v^{3 / 2} \cdot 5 \cdot 2 !}-\frac{\Gamma(9 / 2)}{v^{5 / 2} \cdot 7.3 !}+\cdots\right] \\
=\frac{2}{\sqrt{\pi}} \Gamma(3 / 2) v^{1 / 2}\left[1-\frac{1}{2}\left(\frac{1}{v}\right)+\frac{1.3}{2.4}\left(\frac{1}{v}\right)^{2}-\frac{1.3 .5}{2.4 .6}\left(\frac{1}{v}\right)^{3}\right. \\
+\cdots \cdots \cdots]
\end{array} \\
=v^{1 / 2}\left(1+\frac{1}{v}\right)^{-1 / 2}=\frac{v}{\sqrt{(1+v)}}
\end{gathered}
$$

6. MOHAND TRANSFORM OF

COMPLEMENTARY ERROR FUNCTION:

We have, $\operatorname{erf}(\sqrt{t})+\operatorname{erfc}(\sqrt{t})=1$

$\Rightarrow \operatorname{erfc}(\sqrt{t})=1-\operatorname{erf}(\sqrt{t})$

Applying Mohand transform both sides on equation(8), we have

$M\{\operatorname{erfc}(\sqrt{t})\}=M\{1-\operatorname{erf}(\sqrt{t})\}$

Applying the linearity property of Mohand transform on equation(9), we get

$M\{\operatorname{erfc}(\sqrt{t})\}=M\{1\}-M\{\operatorname{erf}(\sqrt{t})\}$

$\Rightarrow M\{\operatorname{erfc}(\sqrt{t})\}=v-\frac{v}{\sqrt{(1+v)}}$

$\Rightarrow M\{\operatorname{erfc}(\sqrt{t})\}=v\left[\frac{\sqrt{(1+v)}-1}{\sqrt{(1+v)}}\right]$

\section{APPLICATIONS:}

In this section, some applications are given in order to explain the advantage of Mohand transform of error 


\section{International Journal of Research in Advent Technology, Vol.7, No.5, May 2019 \\ E-ISSN: 2321-9637 \\ Available online at www.ijrat.org}

function for evaluating the improper integral, which contain error function.

7.1 Evaluate the improper integral

$I=\int_{0}^{\infty} e^{-t} \operatorname{erf}(\sqrt{t}) d t$

We have $M\{\operatorname{erf}(\sqrt{t})\}=v^{2} \int_{0}^{\infty} \operatorname{erf}(\sqrt{t}) e^{-v t} d t$

$\Rightarrow M\{\operatorname{erf}(\sqrt{t})\}=\frac{v}{\sqrt{(1+v)}}$

Taking $v \rightarrow 1$ in above equation, we have

$I=\int_{0}^{\infty} e^{-t} \operatorname{erf}(\sqrt{t}) d t=\frac{1}{\sqrt{2}}$

7.2 Evaluate the improper integral

$I=\int_{0}^{\infty} t e^{-3 t} \operatorname{erf}(\sqrt{t}) d t$

We have $M\{\operatorname{erf}(\sqrt{t})\}=\frac{v}{\sqrt{(1+v)}}$

$\Rightarrow M\{t \operatorname{erf}(\sqrt{t})\}=\left[\frac{2}{v}-\frac{d}{d v}\right] \frac{v}{\sqrt{(1+v)}}$

$=\frac{2}{\sqrt{(1+v)}}-\frac{2+v}{2(1+v)^{\frac{3}{2}}}$

By the definition of Mohand transform, we have

$M\{t \operatorname{erf}(\sqrt{t})\}=v^{2} \int_{0}^{\infty} t \operatorname{erf}(\sqrt{t}) e^{-v t} d t$

Now by equations (12) and (13), we get

$v^{2} \int_{0}^{\infty} t \operatorname{erf}(\sqrt{t}) e^{-v t} d t=\frac{2}{\sqrt{(1+v)}}-\frac{2+v}{2(1+v)^{\frac{3}{2}}}$

Taking $v \rightarrow 3$ in above equation, we have

$9 \int_{0}^{\infty} t e^{-3 t} \operatorname{erf}(\sqrt{t}) d t=1-\frac{5}{16}=\frac{11}{16}$

$I=\int_{0}^{\infty} t e^{-3 t} \operatorname{erf}(\sqrt{t}) d t=\frac{11}{144}$

7.3 Evaluate the improper integral

$I=\int_{0}^{\infty} e^{-(v-2) t} \operatorname{erf}(\sqrt{t}) d t$

We have $M\{\operatorname{erf}(\sqrt{t})\}=\frac{v}{\sqrt{(1+v)}}$

Now by shifting theorem of Mohand transform, we have

$M\left\{e^{2 t} \operatorname{erf}(\sqrt{t})\right\}=\frac{v^{2}}{(v-2)^{2}}\left[\frac{v-2}{\sqrt{(v-1)}}\right]$

$\Rightarrow M\left\{e^{2 t} \operatorname{erf}(\sqrt{t})\right\}=\frac{v^{2}}{(v-2) \sqrt{(v-1)}}$

By the definition of Mohand transform, we have

$M\left\{e^{2 t} \operatorname{erf}(\sqrt{t})\right\}=v^{2} \int_{0}^{\infty} e^{2 t} \operatorname{erf}(\sqrt{t}) e^{-v t} d t$

$\Rightarrow M\left\{e^{2 t} \operatorname{erf}(\sqrt{t})\right\}=v^{2} \int_{0}^{\infty} e^{-(v-2) t} \operatorname{erf}(\sqrt{t}) d t$

Now by equations (14) and (15), we get

$v^{2} \int_{0}^{\infty} e^{-(v-2) t} \operatorname{erf}(\sqrt{t}) d t=\frac{v^{2}}{(v-2) \sqrt{(v-1)}}$
$\Rightarrow I=\int_{0}^{\infty} e^{-(v-2) t} \operatorname{erf}(\sqrt{t}) d t=\frac{1}{(v-2) \sqrt{(v-1)}}$.

7.4 Evaluate the improper integral

$I=\int_{0}^{\infty} e^{-t}\left\{\int_{0}^{t} \operatorname{erf}(\sqrt{u}) d u\right\} d t$.

We have $M\{\operatorname{erf}(\sqrt{t})\}=\frac{v}{\sqrt{(1+v)}}$

Now by the property of Mohand transform of integral of a function, we have

$M\left\{\int_{0}^{t} \operatorname{erf}(\sqrt{u}) d u\right\}=\frac{1}{v}\left[\frac{v}{\sqrt{(1+v)}}\right]$

$\Rightarrow M\left\{\int_{0}^{t} \operatorname{erf}(\sqrt{u}) d u\right\}=\frac{1}{\sqrt{(1+v)}}$

By the definition of Mohand transform, we have

$M\left\{\int_{0}^{t} \operatorname{erf}(\sqrt{u}) d u\right\}=v^{2} \int_{0}^{\infty} e^{-v t}\left\{\int_{0}^{t} \operatorname{erf}(\sqrt{u}) d u\right\} d t$

Now by equations (16) and (17), we get

$v^{2} \int_{0}^{\infty} e^{-v t}\left\{\int_{0}^{t} \operatorname{erf}(\sqrt{u}) d u\right\} d t=\frac{1}{\sqrt{(1+v)}}$

Taking $v \rightarrow 1$ in above equation, we have

$I=\int_{0}^{\infty} e^{-t}\left\{\int_{0}^{t} \operatorname{erf}(\sqrt{u}) d u\right\} d t=\frac{1}{\sqrt{2}}$

7.5 Evaluate the improper integral

$I=\int_{0}^{\infty} e^{-2 t}\left[\frac{d}{d t} \operatorname{erf}(2 \sqrt{t})\right] d t$

We have $M\{\operatorname{erf}(\sqrt{t})\}=\frac{v}{\sqrt{(1+v)}}$

Now by change of scale property of Mohand transform, we have

$$
\begin{aligned}
& M\{\operatorname{erf}(2 \sqrt{t})\}=4\left[\frac{v / 4}{\sqrt{(1+v / 4)}}\right] \\
& \Rightarrow M\{\operatorname{erf}(2 \sqrt{t})\}=\frac{2 v}{\sqrt{(4+v)}}
\end{aligned}
$$

Now using the property of Mohand transform of derivative of a function, we have

$M\left\{\frac{d}{d t} \operatorname{erf}(2 \sqrt{t})\right\}=v \cdot \frac{2 v}{\sqrt{(4+v)}}-v^{2} \cdot 0$
$\Rightarrow M\left\{\frac{d}{d t} \operatorname{erf}(2 \sqrt{t})\right\}=\frac{2 v^{2}}{\sqrt{(4+v)}}$

By the definition of Mohand transform, we have

$M\left\{\frac{d}{d t} \operatorname{erf}(2 \sqrt{t})\right\}=v^{2} \int_{0}^{\infty} e^{-v t}\left\{\frac{d}{d t} \operatorname{erf}(2 \sqrt{t})\right\} d t$

Now by equations (18) and (19), we get

$v^{2} \int_{0}^{\infty} e^{-v t}\left\{\frac{d}{d t} \operatorname{erf}(2 \sqrt{t})\right\} d t=\frac{2 v^{2}}{\sqrt{(4+v)}}$

Taking $v \rightarrow 2$ in above equation, we have 


\section{Available online at www.ijrat.org}

$4 \int_{0}^{\infty} e^{-2 t}\left\{\frac{d}{d t} \operatorname{erf}(2 \sqrt{t})\right\} d t=\frac{8}{\sqrt{(6)}}$

$\Rightarrow I=\int_{0}^{\infty} e^{-2 t}\left\{\frac{d}{d t} \operatorname{erf}(2 \sqrt{t})\right\} d t=\frac{2}{\sqrt{(6)}}$

$\Rightarrow I=\int_{0}^{\infty} e^{-2 t}\left\{\frac{d}{d t} \operatorname{erf}(2 \sqrt{t})\right\} d t=\sqrt{\frac{2}{3}}$.

7.6 Evaluate the improper integral

$I=\int_{0}^{\infty} e^{-5 t}[\operatorname{erf} \sqrt{t} * \operatorname{erf} \sqrt{t}] d t$.

By convolution theorem of Mohand transform, we have

$M\{\operatorname{erf} \sqrt{t} * \operatorname{erf} \sqrt{t}\}=\frac{1}{v^{2}} M\{\operatorname{erf}(\sqrt{t})\} M\{\operatorname{erf}(\sqrt{t})\}$

$=\frac{1}{v^{2}}\left[\frac{v}{\sqrt{(1+v)}}\right]\left[\frac{v}{\sqrt{(1+v)}}\right]=\frac{1}{1+v}$

Now by the definition of Mohand transform, we have

$$
M\{\operatorname{erf} \sqrt{t} * \operatorname{erf} \sqrt{t}\}=v^{2} \int_{0}^{\infty} e^{-v t}\{\operatorname{erf} \sqrt{t} * \operatorname{erf} \sqrt{t}\} d t
$$

Now by equations (20) and (21), we get

$v^{2} \int_{0}^{\infty} e^{-v t}\{\operatorname{erf} \sqrt{t} * \operatorname{erf} \sqrt{t}\} d t=\frac{1}{1+v}$

Taking $v \rightarrow 5$ in above equation, we have

$25 \int_{0}^{\infty} e^{-5 t}\{\operatorname{erf} \sqrt{t} * \operatorname{erf} \sqrt{t}\} d t=\frac{1}{6}$

$\Rightarrow I=\int_{0}^{\infty} e^{-5 t}\{\operatorname{erf} \sqrt{t} * \operatorname{erf} \sqrt{t}\} d t=\frac{1}{150}$.

\section{CONCLUSIONS:}

In this article, we have successfully discussed the Mohand transform of error function. The given numerical applications in application section show the advantage of Mohand transform of error function for evaluating the improper integral, which contain error function. Results of numerical applications show Mohand transform give the exact solution without any tedious calculation work.

\section{REFERENCES}

[1] Aggarwal, S., Gupta, A.R., Singh, D.P., Asthana, N. and Kumar, N., Application of Laplace transform for solving population growth and decay problems, International Journal of Latest Technology in Engineering, Management \& Applied Science, 7(9), 141-145, 2018.

[2] Lokenath Debnath and Bhatta, D., Integral transforms and their applications, Second edition, Chapman \& Hall/CRC, 2006.

[3] Chauhan, R. and Aggarwal, S., Solution of linear partial integro-differential equations using Mahgoub transform, Periodic Research, 7(1), 2831, 2018.
[4] Aggarwal, S., Sharma, N., Chauhan, R., Gupta, A.R. and Khandelwal, A., A new application of Mahgoub transform for solving linear ordinary differential equations with variable coefficients, Journal of Computer and Mathematical Sciences, 9(6), 520-525, 2018.

[5] Aggarwal, S., Chauhan, R. and Sharma, N., A new application of Mahgoub transform for solving linear Volterra integral equations, Asian Resonance, 7(2), 46-48, 2018.

[6] Aggarwal, S., Sharma, N. and Chauhan, R., Solution of linear Volterra integro-differential equations of second kind using Mahgoub transform, International Journal of Latest Technology in Engineering, Management \& Applied Science, 7(5), 173-176, 2018.

[7] Aggarwal, S., Sharma, N. and Chauhan, R., Application of Mahgoub transform for solving linear Volterra integral equations of first kind, Global Journal of Engineering Science and Researches, 5(9), 154-161, 2018.

[8] Aggarwal, S., Pandey, M., Asthana, N., Singh, D.P. and Kumar, A., Application of Mahgoub transform for solving population growth and decay problems, Journal of Computer and Mathematical Sciences, 9(10), 1490-1496, 2018.

[9] Aggarwal, S., Sharma, N. and Chauhan, R., Mahgoub transform of Bessel's functions, International Journal of Latest Technology in Engineering, Management \& Applied Science, 7(8), 32-36, 2018.

[10] Aggarwal, S., Gupta, A.R., Sharma, S.D., Chauhan, R. and Sharma, N., Mahgoub transform ( LaplaceCarson transform) of error function, International Journal of Latest Technology in Engineering, Management \& Applied Science, 8(4), 92-98, 2019.

[11] Gupta, A.R., Solution of Abel's integral equation using Mahgoub transform method, Journal of Emerging Technologies and Innovative Research, 6(4), 252-260, 2019.

[12] Aggarwal, S. and Gupta, A.R., Solution of linear Volterra integro-differential equations of second kind using Kamal transform, Journal of Emerging Technologies and Innovative Research, 6(1), 741747, 2019.

[13] Aggarwal, S. and Sharma, S.D., Application of Kamal transform for solving Abel's integral equation, Global Journal of Engineering Science and Researches, 6(3), 82-90, 2019.

[14] Aggarwal, S., Chauhan, R. and Sharma, N., A new application of Kamal transform for solving linear Volterra integral equations, International Journal of 


\section{International Journal of Research in Advent Technology, Vol.7, No.5, May 2019 E-ISSN: 2321-9637 Available online at www.ijrat.org}

Latest Technology in Engineering, Management \& Applied Science, 7(4), 138-140, 2018.

[15] Gupta, A.R., Aggarwal, S. and Agrawal, D., Solution of linear partial integro-differential equations using Kamal transform, International Journal of Latest Technology in Engineering, Management \& Applied Science, 7(7), 88-91, 2018.

[16] Aggarwal, S., Sharma, N. and Chauhan, R., Application of Kamal transform for solving linear Volterra integral equations of first kind, International Journal of Research in Advent Technology, 6(8), 2081-2088, 2018.

[17] Aggarwal, S., Gupta, A.R., Asthana, N. and Singh, D.P., Application of Kamal transform for solving population growth and decay problems, Global Journal of Engineering Science and Researches, 5(9), 254-260, 2018.

[18] Aggarwal, S., Kamal transform of Bessel's functions, International Journal of Research and Innovation in Applied Science, 3(7), 1-4, 2018.

[19] Aggarwal, S., Sharma, N. and Chauhan, R., Application of Aboodh transform for solving linear Volterra integro-differential equations of second kind, International Journal of Research in Advent Technology, 6(6), 1186-1190, 2018.

[20] Aggarwal, S., Sharma, N. and Chauhan, R., A new application of Aboodh transform for solving linear Volterra integral equations, Asian Resonance, 7(3), 156-158, 2018.

[21] Aggarwal, S., Asthana, N. and Singh, D.P., Solution of population growth and decay problems by using Aboodh transform method, International Journal of Research in Advent Technology, 6(10), 2706-2710, 2018.

[22] Aggarwal, S., Sharma, N. and Chauhan, R., Application of Aboodh transform for solving linear Volterra integral equations of first kind, International Journal of Research in Advent Technology, 6(12), 3745-3753, 2018.

[23] Aggarwal, S. and Sharma, S.D., Solution of Abel's integral equation by Aboodh transform method, Journal of Emerging Technologies and Innovative Research, 6(4), 317-325, 2019.

[24] Aggarwal, S., Gupta, A.R. and Agrawal, D., Aboodh transform of Bessel's functions, Journal of Advanced Research in Applied Mathematics and Statistics, 3(3), 1-5, 2018.

[25] Aggarwal, S., Sharma, N. and Chauhan, R., Solution of population growth and decay problems by using Mohand transform, International Journal of Research in Advent Technology, 6(11), 32773282, 2018.
[26] Aggarwal, S., Sharma, N. and Chauhan, R., Solution of linear Volterra integral equations of second kind using Mohand transform, International Journal of Research in Advent Technology, 6(11), 3098-3102, 2018.

[27] Aggarwal, S., Chauhan, R. and Sharma, N., Mohand transform of Bessel's functions, International Journal of Research in Advent Technology, 6(11), 3034-3038, 2018.

[28] Aggarwal, S., Sharma, S.D. and Gupta, A.R., A new application of Mohand transform for handling Abel's integral equation, Journal of Emerging Technologies and Innovative Research, 6(3), 600608, 2019.

[29] Aggarwal, S. and Chaudhary, R., A comparative study of Mohand and Laplace transforms, Journal of Emerging Technologies and Innovative Research, 6(2), 230-240, 2019.

[30] Aggarwal, S., Sharma, N., Chaudhary, R. and Gupta, A.R., A comparative study of Mohand and Kamal transforms, Global Journal of Engineering Science and Researches, 6(2), 113-123, 2019.

[31] Aggarwal, S., Mishra, R. and Chaudhary, A., A comparative study of Mohand and Elzaki transforms, Global Journal of Engineering Science and Researches, 6(2), 203-213, 2019.

[32] Aggarwal, S. and Chauhan, R., A comparative study of Mohand and Aboodh transforms, International Journal of Research in Advent Technology, 7(1), 520-529, 2019.

[33] Aggarwal, S. and Sharma, S.D., A comparative study of Mohand and Sumudu transforms, Journal of Emerging Technologies and Innovative Research, 6(3), 145-153, 2019.

[34] Aggarwal, S., Chauhan, R. and Sharma, N., Application of Elzaki transform for solving linear Volterra integral equations of first kind, International Journal of Research in Advent Technology, 6(12), 3687-3692, 2018.

[35] Aggarwal, S., Singh, D.P., Asthana, N. and Gupta, A.R., Application of Elzaki transform for solving population growth and decay problems, Journal of Emerging Technologies and Innovative Research, 5(9), 281-284, 2018.

[36] Aggarwal, S., Elzaki transform of Bessel's functions, Global Journal of Engineering Science and Researches, 5(8), 45-51, 2018.

[37] Aggarwal, S., Sharma, S.D. and Gupta, A.R., Application of Shehu transform for handling growth and decay problems, Global Journal of Engineering Science and Researches, 6(4), 190198, 2019. 


\section{International Journal of Research in Advent Technology, Vol.7, No.5, May 2019 E-ISSN: 2321-9637 Available online at www.ijrat.org}

[38] Aggarwal, S., Gupta, A.R. and Sharma, S.D., A new application of Shehu transform for handling Volterra integral equations of first kind, International Journal of Research in Advent Technology, 7(4), 439-445, 2019.

[39] Aggarwal, S. and Gupta, A.R., Sumudu transform for the solution of Abel's integral equation, Journal of Emerging Technologies and Innovative Research, 6(4), 423-431, 2019.

[40] Aggarwal, S., A comparative study of Mohand and Mahgoub transforms, Journal of Advanced Research in Applied Mathematics and Statistics, 4(1), 1-7, 2019.

[41] Mahgoub, M.A.M. and Alshikh, A.A., An application of new transform "Mahgoub Transform" to partial differential equations, Mathematical Theory and Modeling, 7(1), 7-9, 2017.

[42] Fadhil, R.A., Convolution for Kamal and Mahgoub transforms, Bulletin of Mathematics and Statistics Research, 5(4), 11-16, 2017.

[43] Taha, N.E.H., Nuruddeen, R.I., Abdelilah, K. and Hassan, S., Dualities between "Kamal \& Mahgoub integral transforms" and "Some famous integral transforms", British Journal of Applied Science \& Technology, 20(3), 1-8, 2017.

[44] Abdelilah, K. and Hassan, S., The use of Kamal transform for solving partial differential equations, Advances in Theoretical and Applied Mathematics, 12(1), 7-13, 2017.

[45] Abdelilah, K. and Hassan, S., The new integral transform "Kamal Transform", Advances in Theoretical and Applied Mathematics, 11(4), 451458, 2016.

[46] Aboodh, K.S., Application of new transform "Aboodh Transform" to partial differential equations, Global Journal of Pure and Applied Mathematics, 10(2), 249-254, 2014.

[47] Aboodh, K.S., Farah, R.A., Almardy, I.A. and Osman, A.K., Solving delay differential equations by Aboodh transformation method, International Journal of Applied Mathematics \& Statistical Sciences, 7(2), 55-64, 2018.

[48] Aboodh, K.S., Farah, R.A., Almardy, I.A. and Almostafa, F.A., Solution of partial integrodifferential equations by using Aboodh and double Aboodh transforms methods, Global Journal of Pure and Applied Mathematics, 13(8), 4347-4360, 2016.

[49] Mohand, M. and Mahgoub, A., The New Integral Transform "Mohand Transform", Advances in Theoretical and Applied Mathematics, 12(2), 113 120, 2017.
[50] Kumar, P.S., Saranya, C., Gnanavel, M.G. and Viswanathan, A., Applications of Mohand transform for solving linear Volterra integral equations of first kind, International Journal of Research in Advent Technology, 6(10), 2786-2789, 2018.

[51] Kumar, P.S., Gomathi, P., Gowri, S. and Viswanathan, A., Applications of Mohand transform to mechanics and electrical circuit problems, International Journal of Research in Advent Technology, 6(10), 2838-2840, 2018.

[52] Sathya, S. and Rajeswari, I., Applications of Mohand transform for solving linear partial integrodifferential equations, International Journal of Research in Advent Technology, 6(10), 2841-2843, 2018.

[53] Elzaki, T.M., The new integral transform "Elzaki Transform", Global Journal of Pure and Applied Mathematics, 1, pp. 57-64, 2011.

[54] Elzaki, T.M. and Ezaki, S.M., On the Elzaki transform and ordinary differential equation with variable coefficients, Advances in Theoretical and Applied Mathematics, 6(1), 41-46, 2011.

[55] Elzaki, T.M. and Ezaki, S.M., Applications of new transform "Elzaki transform"' to partial differential equations, Global Journal of Pure and Applied Mathematics, 7(1), 65-70, 2011.

[56] Maitama, S. and Zhao, W., New integral transform: Shehu transform a generalization of Sumudu and Laplace transform for solving differential equations, International Journal of Analysis and Applications, 17(2), 167-190, 2019.

[57] Watugula, G.K., Sumudu transform: A new integral transform to solve differential equations and control engineering problems, International Journal of Mathematical Education in Science and Technology, 24(1), 35-43, 1993.

[58] Belgacem, F.B.M. and Karaballi, A.A., Sumudu transform fundamental properties investigations and applications, Journal of Applied Mathematics and Stochastic Analysis, 1-23, 2006.

[59] Zill, D.G., Advanced engineering mathematics, Jones \& Bartlett, 2016.

[60] Korn, G.A. and Korn, T.M., Mathematical handbook for scientists and engineers: Definitions, theorems and formulas for reference and review, Dover Publications, 2000.

[61] Zill, D.G., A first course in differential equations with modeling applications, Brooks Cole, 2008.

[62] Readey, D.W., Kinetics in materials science and engineering, CRC Press, 2017. 
International Journal of Research in Advent Technology, Vol.7, No.5, May 2019

E-ISSN: 2321-9637

Available online at www.ijrat.org

[63] Andrews, L.C., Special functions of mathematics for engineers, Second edition, SPIE Publications, 1997.
[64] Andrews, L.C., Field guide to special functions for engineers, SPIE Press, 2011. 